\title{
Comparison between Electroacupuncture, Detomidine Plus Electroacupuncture and Detomidine Alone for Laparoscopic Surgery in Goats
}

Khalifa Ashour ${ }^{1}$, Naglaa Abd Elkader Awad ${ }^{2}$, Sherein Saeid Abdelgayed ${ }^{3}$, Amal Z. Leil ${ }^{*}$ and Eldessouky Sheta ${ }^{2}$

\author{
${ }^{1} \mathrm{PhD}$. Scholar, Tripoli, Libya.
}

${ }^{2}$ Department of Surgery, Anaesthesiology and Radiology, Faculty of Veterinary Medicine, Cairo University, Egypt.

${ }^{3}$ Department of Pathology, Faculty of Veterinary Medicine, Cairo University, Egypt.

${ }^{4}$ Department of Field Investigation, Animal Reproduction Research Institute, Agriculture Research Center (ARC), Giza, Egypt.

"Corresponding Author, Amal Z. Leil, E-mail: amal_leil@yahoo.com

\begin{abstract}
This study aimed to validate the effectiveness of electroacupuncture (EA), detomidine plus electroacupuncture and detomidine alone for laparoscopy in goats in terms of physiological variables, vital parameters, CBC and pain threshold. Fifteen healthy adult bucks divided into 3 groups (5 bucks/group); (group I) received electroacupuncture at 10 newly selected acupoints, (group II) get electroacupuncture plus detomidine and (group III) administered detomidine alone. The obtained data $(\mathrm{M} \pm \mathrm{SD})$ were assessed at intervals ( $0 \mathrm{~min}$.) before induction, (5 min.), (10 min.), (15 min.) and (20 min.) during induction, (30 $\mathrm{min}$.$) , (45 \mathrm{min}$.$) and (60 \mathrm{min}$. throughout surgery and (24 hr) post-surgery, cortisol levels in serum at (0), $(24 \mathrm{hr})$, and $(72 \mathrm{hr})$ throughout laparoscopy. Group (I) showed improvement of the rates of eyelid closure, head and neck relaxation, rumen motility, and tympany. The respiratory rates, the body temperatures and capillary fill times for the three groups were not significantly different. Hematocrit, Hemoglobin, RBCs, Platelets and oxygen saturation (SpO2) were significant. ALT and AST showed no significance. Cortisol and pain threshold showed significant difference. Thus, electroacupuncture could be recommended for goat laparoscopic surgery as it works more potent and achieves sufficient abdominal anaesthesia superior to the other two regimes.
\end{abstract}

Original Article:

DOI:

https://dx.doi.org/10.21608/javs.20

20.120351

Received : 22 Sept., 2020.

Accepted :24 Oct., 2020.

Published in October, 2020.

This is an open access article under the term of the Creative Commons Attribution 4.0 (CCBY) International License. To view a copy of this license, visit:

http://creativecommons.org/licenses/by/4.0/

J. Appl. Vet. Sci., 5(4): $73-83$.

Keywords: Anaesthesia, detomidine, electroacupuncture, Goat, laparoscopy.

\section{INTRODUCTION}

Electroacupuncture (EA) involves electrical stimulation of acupoints via inserted needles. This procedure was first introduced in 1960 and was successfully used to relieve pain during Caesarean section, gastrectomy, enterectomy, and castration in domestic animals along with maintaining a stable physiologic index (Parmen, 2014). The combination of electroacupuncture and antinociceptors was successfully used during surgeries. This combination improved antinociceptive effects and also minimized some drug-induced adverse effects (Wang et al., 1995; Dong and Wang, 2006). Electroacupuncture, in combination with analgesics, reduces required dosages of analgesics in human (Wang and Jin, 1989), rats (Tang et al., 1997) and goats (Liu et al., 2009). It is clear that the antinociceptive effect induced by electroacupuncture in goats (ruminants) is superior to that in humans or rats. However, effectiveness of the combined use of electroacupuncture and $\alpha 2$ adrenoceptor agonists for ruminants remains unclear (Zahir $\boldsymbol{e t}$. al.,2016). Detomidine, alpha2 adrenoceptor agonist, is a more potent sedative and analgesic than xylazine (Virtanen and MacDonald, 1985).

Abdominal surgery has been done in animals under electroacupuncture analgesia (Rogers, 1995; Sheta et al., 2015). There are many techniques involved with goat surgery aimed to achieve the best results in all surgical interferences that has been approved to be safe to the animal physiology. This reason is enough to change believing in drugs and its 


\section{Comparison between Electroacupuncture, Detomidine Plus Electroacupuncture ........}

adverse effects into the idea of using electroacupuncture as one of the alternative therapies in production of analgesia for surgical interferences in dogs (Groppetti et al., 2011). Pain is blocked by acupoints stimulation with the release of endogenous opioids and neurotransmitters (Janssens et al., 1988).

In ruminants, exploratory laparoscopy can be use both as a diagnostic and therapeutic tool in various diseases affecting the abdominal organs (Leil, 2006; Pugh and Baird, 2020). Numerous research investigations have required exploration and examination abdominal contents of the sheep and goat, because these species are available and relatively inexpensive (Hulet and Foote, 1968).

Laparoscopy is a minimally invasive technique for exploring the internal organs of the abdominal cavity. The equipment used during laparoscopy provides a live picture of the insides of the abdominal cavity (Freeman, 1999). Laparoscopy has many diagnostic, therapeutic, and prognostic applications (Chamness, 2002).

The purpose of the study reported here was to investigate the effectiveness of Electroacupuncture, Detomidine plus Electroacupuncture and Detomidine Alone on the physiological variables, cortisol and pain threshold For Laparoscopy in Goats.

\section{MATERIALS AND METHODS}

Study plan: the study was conducted on 15 healthy uncastrated bucks (mean \pm SD age, $1.72 \pm 0.08$ years; mean body weight $37.27 \pm 0.89 \mathrm{~kg}$ ). The bucks were placed under identical conditions and fed on concentrates, green fodder and allowed to graze for four hours a day. Physiological variables, vital parameters, CBC, ALT and AST were analyzed and recorded at intervals; $0 \mathrm{~min}$ (before induction), $5 \mathrm{~min}$, $10 \mathrm{~min}, 15 \mathrm{~min}, 20 \mathrm{~min}$ during induction, $30 \mathrm{~min}, 45$ min, 60 min during surgery and 24 hours post-surgery. Cortisol levels in serum at $0,24 \mathrm{hr}$ and $72 \mathrm{hr}$ were estimated (Cadoy and Acorda, 2018). SpO2 was measured by Infunix technology Pure scope IP-3050 (Pugh et al., 2020).

\section{Experimental surgery design:}

Ethical Committee Faculty of Veterinary Medicine, Cairo University, Cairo, Egypt (The experimental protocol CU06202019053) for electroacupuncture stimulation of goats for laparotomy and laparoscopy to be performed at the Department of Surgery, Anesthesiology and Radiology. Laparotomy was carried out on bucks that were divided into 3 groups; group (I) 5 bucks received electroacupuncture in 10 newly advocated acupoints, group (II) 5 bucks obtained electroacupuncture and detomidine (DOMOSEDAN, Vetoquinol; $0.03 \mathrm{mg} / \mathrm{kg}$, IM, whereas
$1 \mathrm{ml}$ added to $9 \mathrm{ml}$ distilled water, each buck injected $1 \mathrm{ml}$ of the diluted solution), and group (III) 5 bucks administered detomidine alone $(0.03 \mathrm{mg} / \mathrm{kg}$, IM). Laparoscopy was carried out in all bucks according to the methodology of Leil (2006), El-Khamar (2008) and Celarier et al. (2020). In brief, the abdominal region was surgically prepared by shaving the hair and disinfecting the skin. Using the cradle, the buck was positioned in a supine head-down (Trendelenburg) position to an approximate angle of 450 .

A scalpel blade was used to make a small skin incision in order to create pneumoperitoneum with $\mathrm{CO} 2$ using Verus needle $5-10 \mathrm{~cm}$ on each side of the midline (linea alba). The 2-mm Verus needle that was connected with the $\mathrm{CO} 2$ is first introduced and the abdomen was inflated to reduce the chance of injury to organs and to facilitate trocar penetration. The trocars and cannulae for introducing laparoscope were inserted and the sharp trocar was withdrawn as soon as the abdominal wall has been penetrated. The blunt cannula was pushed well into the abdomen. Instruments were withdrawn and putted into disinfectants between each animal. An antibiotic spray was applied to the wounds before it was sutured using absorbable sutures (Proline). Heart rate (HR), Respiratory rate (RR), rectal temperature and haematological analysis were performed for all bucks.

Electroacupunture stimulator (Fig. 1) KWD 808I- multipurpose health device, delivers a bipolar waveform (+) and (-) at each electrode through needles in the correct points. It induces dense dispersed wave output at frequencies $20-30 \mathrm{~Hz}$ for surgery (Sheta, et al., 2015). Acupuncture sites shaved, antiseptically prepared with $10 \%$ povidone-iodine solution and the sterile acupuncture needles inserted into the points. Renewal of the previously selected acupoints (Soo-jin et al., 2005; Zahir et al., 2016) were pointed out in Fig. (2).

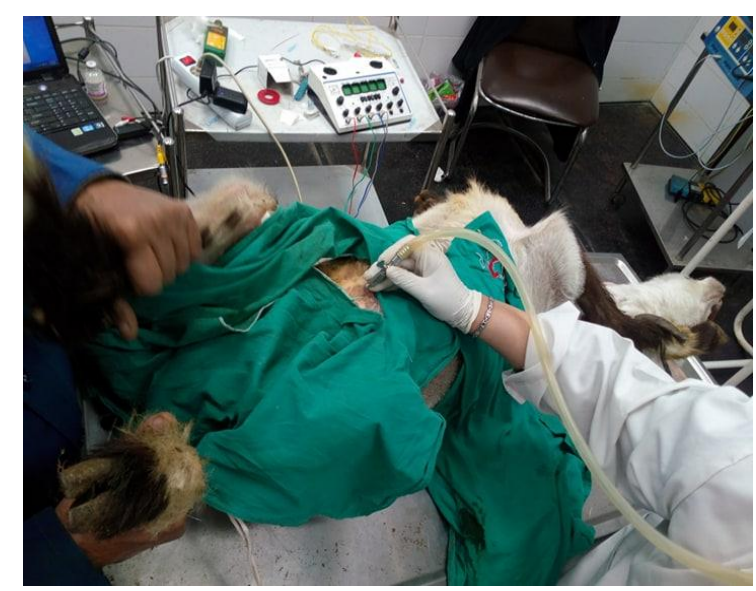

Fig 1. Showing stimulator of electroacupuncture and laparoscopy 


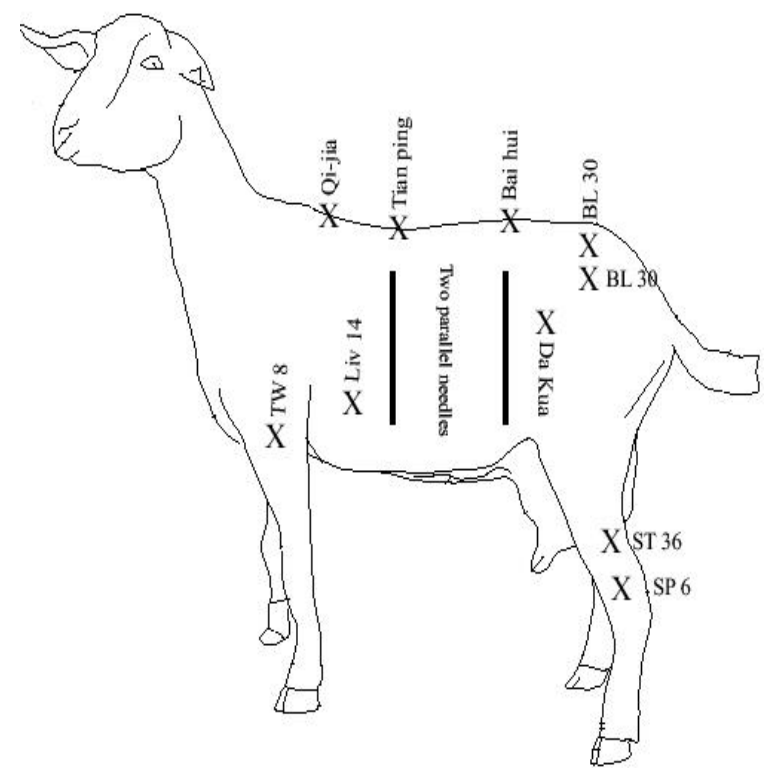

Fig. 2. Map of the chosen acupoint.

For surgery, the bucks starved for 24 hours and water withheld for 6 hours prior to induction of anaesthesia. The start of the experiment was the moment when EA started (0 minutes). During EA stimulation, the first 20 minutes were regarded as the induction period of EA analgesia, followed by 60 minutes as the maintenance period of EA analgesia. This maintenance time was based on our experiences of commonly performed surgeries.

The ten newly selected acupoints for laparoscopic surgery in bucks which nomenclatured as Qi-jia (Withers) (+ve) concerted with St 36 (Tsu-SanLi) (-ve); Tianping (+ve) conecrted along Da-Kua (Greater Trochanter) (-ve); Gov 20 (Baihui) (+ve) concerted with Sp 6 (Sanyinjao) (-ve); BL 30 (Baihuanshu) (+ve) along Liv 14 (Chimen) (-ve) \& BL 30 (Baihuanshu) (+ve) connected to TW 8 (Triple Warmer or Triple Heater) (-ve). In addition to twoparallel needles, away from each other inserted subcutaneously and muscle layers in the surgery area Table (1).

\section{Pain threshold recording}

The experimental bucks of the study were restraint by casting at tilting operation table to perform laparoscopic surgery. The pain threshold was measured at the center of the left flank. Two electrodes were placed 1 to $2 \mathrm{~cm}$ apart on the skin. Digital Multipara meter monitor, Shenzhen (VL9205A), apparatus was used to deliver the pulsed direct current to the electrodes, which forced potassium ions into the subcutaneous tissues. Voltage was continuously increased. Pain threshold voltage was recorded at the moment when obvious contractions of the local skin and muscles, turning of the head toward the abdomen, hunching of the back, and evasive body movements were observed. The electric current was then turned off. Measurement of pain threshold was repeated 5 times. Percentage change in the pain threshold was calculated as follows: Percentage change $=([\mathrm{Vn}-$ $\mathrm{V} 0] / \mathrm{V} 0) \mathrm{X} 100 \%$ where $\mathrm{Vn}$ is the mean voltage for the pain threshold during the experiment and $\mathrm{VO}$ is the mean voltage for the pain threshold before the experiment (time 0 ).

Post- surgery, prophylactic antibiotic $(250,000$ units of penicillin and $250 \mathrm{mg}$ Dihydrostreptomycin per $10 \mathrm{~kg}$ body weight), was injected intramuscularly to each buck once daily for five consecutive days.

\section{Statistical analyses}

Data were analyzed using PASW Statistics, Version 18.0 software (SPSS Inc., Chicago, IL, USA). Results were compared by Two-way Repeated Measure ANOVA. A P-value $<0.05$ was considered statistically significant. 
Table :1. The selected acupoints and location for abdominal surgery in goats.

\begin{tabular}{|c|c|}
\hline Acupoints & Location \\
\hline Qi-jia (Withers) & $\begin{array}{l}\text { Located between GV-13 and GV-14; it located in the depression along midline } \\
\text { between 3rd thoracic and 4th thoracic vertebrae or at the most elevated point in } \\
\text { the withers. It was reached by perpendicular insertion with round sharp needle } 2 \\
\text { cm deep, under the ligamentum supraspinale. }\end{array}$ \\
\hline Tianping & $\begin{array}{l}\text { Located on the dorso-median line in the center of the depression between the } \\
\text { neural spines of the thirteenth thoracic and first lumbar vertebrae. The needle } \\
\text { passed to a depth of } 1.5-2 \text { centimeters. }\end{array}$ \\
\hline Gov 20 (Baihui) & $\begin{array}{l}\text { Located on the dorso-median line in the center of the depression between the } \\
\text { neural spines of the last lumbar and first sacral vertebrae. The needle was passed } \\
\text { perpendicularly to a depth of } 1.5 \text { to } 2 \text { centimeters, penetrating the fascia } \\
\text { supraspinous ligament and extending up to the dura mater }\end{array}$ \\
\hline BL 30 (Baihuanshu) & $\begin{array}{l}\text { Located at the caudal part of the lateral sacral crest and about } 6 \text { centimeters from } \\
\text { the middorsal line. The needle at this point penetrated subcutaneously downwards } \\
\text { and forward to a distance of } 0.5 \text { to } 1.0 \text { centimeter. This point was bilateral. }\end{array}$ \\
\hline $\begin{array}{c}\text { Da-Kua (Greater } \\
\text { Trochanter) }\end{array}$ & $\begin{array}{l}\text { Located } 6 \mathrm{~cm} \text { cranioventral to the greater trochanter of the femur. It reached by } \\
\text { angular insertion caudoventrally with round sharp needle } 2 \mathrm{~cm} \text { deep, in the } \\
\text { depression between musculi tensor fasciae lata and gluteus superficialis. }\end{array}$ \\
\hline Sp 6 (Sanyinjao): & $\begin{array}{l}\text { Located on the medial surface of the leg just behind tibia and approximately } 1.5 \\
\text { centimeters cranial to the medial malleolus. The needle was passed } \\
\text { subcutaneously in an upward direction to a length of } 1.5-2 \text { centimeters. }\end{array}$ \\
\hline St 36 (Tsu-San-Li) & $\begin{array}{l}\text { Located at the. dorsolateral aspect of the leg, about } 2.5 \text { centimeters distal to the } \\
\text { head of the fibula near the base of the tibial crest. The needle was passed } \\
\text { obliquely towards the foot to a distance of } 1.5-2 \text { centimeters. }\end{array}$ \\
\hline Liv 14 (Chimen) & $\begin{array}{l}\text { Located on the lateral aspect of the thorax at the } 8 \text { th intercostal space on a level } \\
\text { with the point of elbow. The needle at this point was passed subcutaneously to a } \\
\text { depth of } 1.5 \text { - } 2 \text { centimeters in a downward direction. }\end{array}$ \\
\hline TW 8 (Triple Warmer) & $\begin{array}{l}\text { Located at a point about } 6 \text { centimeters below the elbow on the lateral groove of } \\
\text { the forearm about } 1.5-3 \text { centimeters ventral to the lateral ligament of radius. The } \\
\text { needle at this point directed at an angle of } 20 \text { degrees along the posterior border of } \\
\text { radius and then passed posterior medially to a depth of } 6 \text { centimeters. The tip of } \\
\text { the needle could felt on the medial side }\end{array}$ \\
\hline Two-parallel needles & $\begin{array}{l}\text { away from each other inserted subcutaneously and muscle layers at the surgery } \\
\text { area }\end{array}$ \\
\hline
\end{tabular}




\section{RESULTS}

\section{Physiological findings}

\section{Laparoscopy physiological variables}

The eyelid closure rates for all groups were significantly different, where the group (I) showed the highest eyelid closure rate, followed by group (III). The rate of head and neck relaxation for groups (I) and (II) were significantly higher than that of group (III). The rate of head and neck relaxation for the group (I) was not significantly differ. The rate of tympany was graded into mild $(+)$, moderate $(++)$, and sever $(+++)$, groups (II) and (III) were significantly lower than the group (I). But for group (II) did not significantly differ from that of the group III (diagram 1).
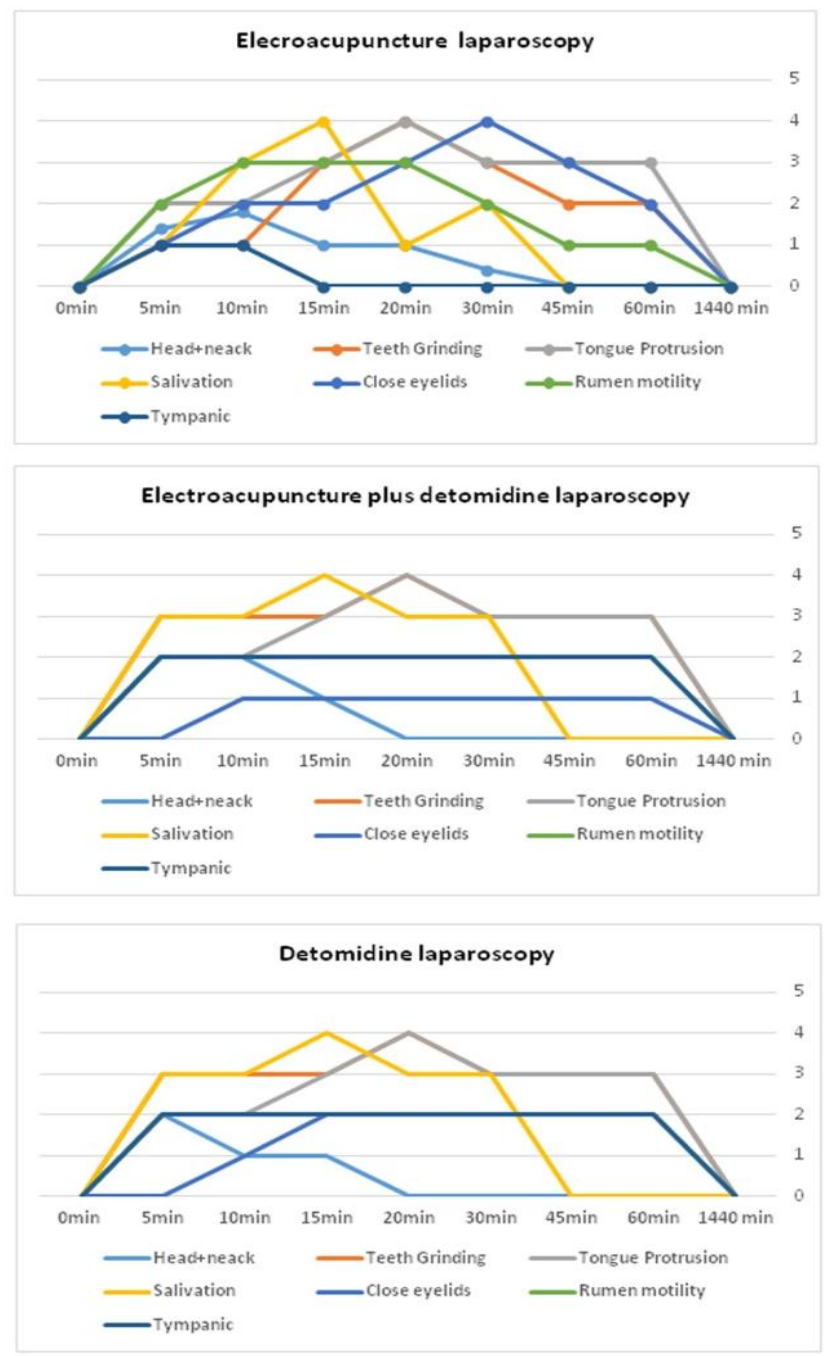

Diagram 1: The physiological variables between the three groups.

\section{Vital parameters findings Laparoscopy vital parameters}

The heart rate for groups (II) and (III) were significantly lower than the group (I). Also, the heart rate of the group (II) did not significantly differ from that of the group III (diagram 2). The mean body temperature of the group (I) is significantly higher than the group (III). The mean body temperature of group (II) did not significantly differ from that of groups (I) and III (diagram 3). The respiratory rates for group (II) were significantly lower than that of the group (I). Also, the respiratory rate of groups (I) and (II) did not significantly differ from that of the group III (diagram 4). The mean capillary fill times for all the three groups were not significantly different (diagram 5).

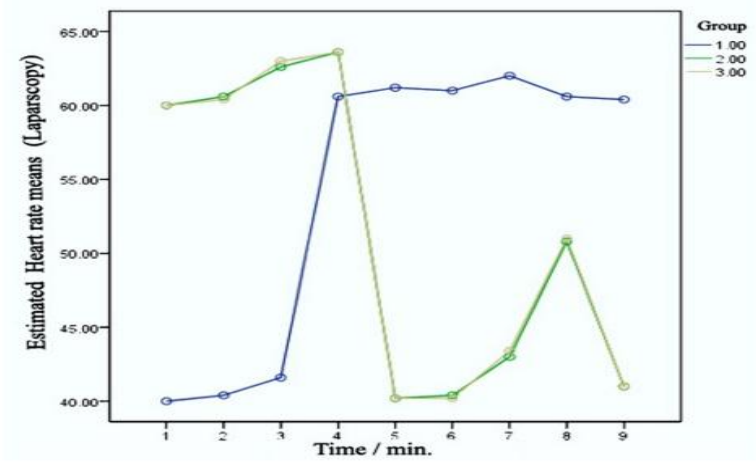

Diagram 2: Heart rates between the three groups in laparoscopy

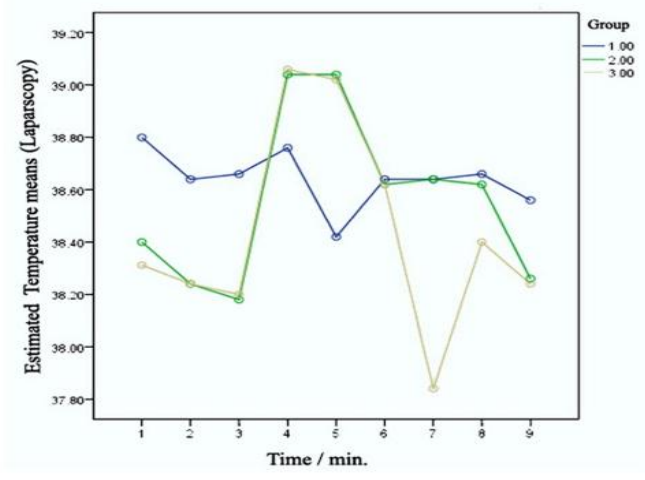

Diagram 3: Estimated temperatures between the three groups in laparoscopy

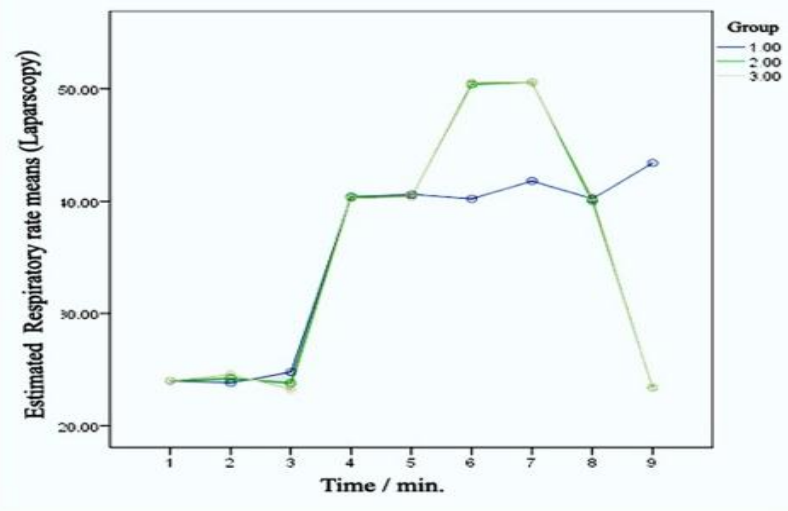

Diagram 4: Respiratory rates between the three groups in laparoscopy. 


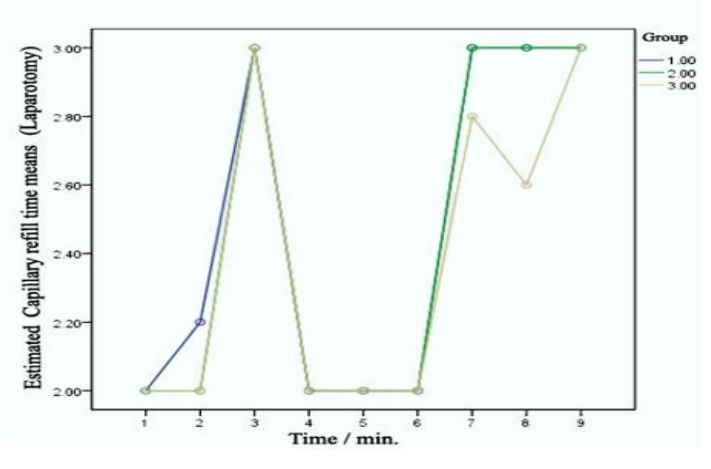

Diagram 5: Capillary refill times between the three groups in laparoscopy

\section{Hematological findings}

\section{Laparoscopy hematologic parameters}

The eosinophils $(3.4 \pm 1.45)$, diagram (6). Capillary refill times between the three groups in laparoscopy, hematocrit (22.6 \pm 3.7), diagram (7).Capillary refill times between the three groups in laparoscopy, lymphocytes $(55.4 \pm 8.64)$ diagram (8). Capillary refill times between the three groups in laparoscopy, monocytes $(7 \pm 2.35)$ diagram (9). Capillary refill times between the three groups in laparoscopy, platelets $(269086.7 \pm 95995.3)$ diagram (10). Capillary refill times between the three groups in laparoscopy, RBCs $(9.15 \pm 1.49)$ diagram (11).

Capillary refill times between the three groups in laparoscopy, segmented cells $(32.9 \pm 10.5)$ diagram (12). Capillary refill times between the three groups in laparoscopy, $\mathrm{SpO} 2(71.3 \pm 0.45)$ of the three groups were significantly different. Group (III) recorded the highest eosinophils, lymphocytes, and segmented cells, followed by group II diagram (13). Capillary refill times between the three groups in laparoscopy. Group (II) recorded the highest $\mathrm{SpO} 2$ levels, followed by the group (III). Group (I) recorded the highest hematocrit, monocytes, platelets, and RBCs levels, followed by a group (III). The WBCs $(105760.1 \pm 84170.5)$ diagram (14). Capillary refill times between the three groups in laparoscopy count of groups (II) and (III) were significantly higher than group (I). The WBCs count of group (II) did not significantly differ from that of the group (III).

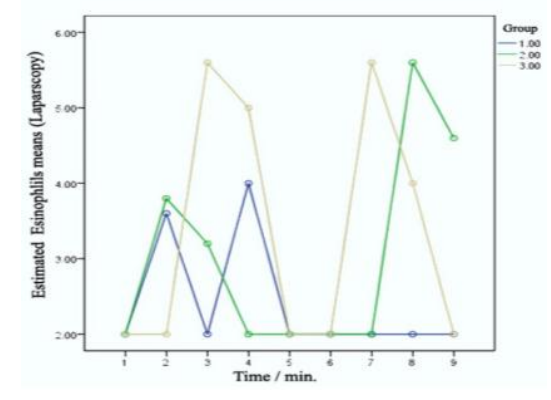

Diagram 6: Esinophils between the three groups in laparoscopy.

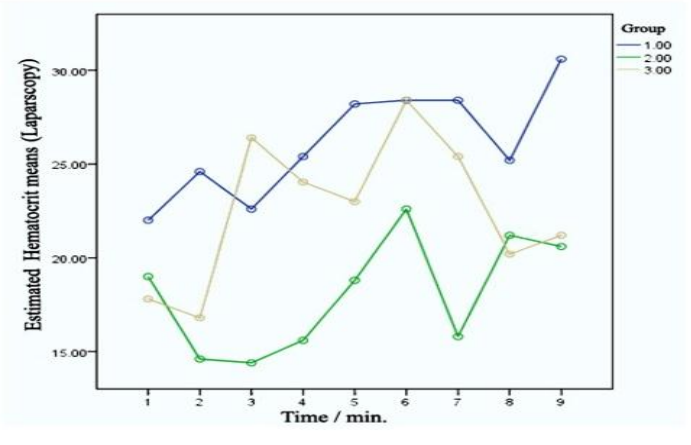

Diagram 7: Hematocrit values between the three groups in laparoscopy.

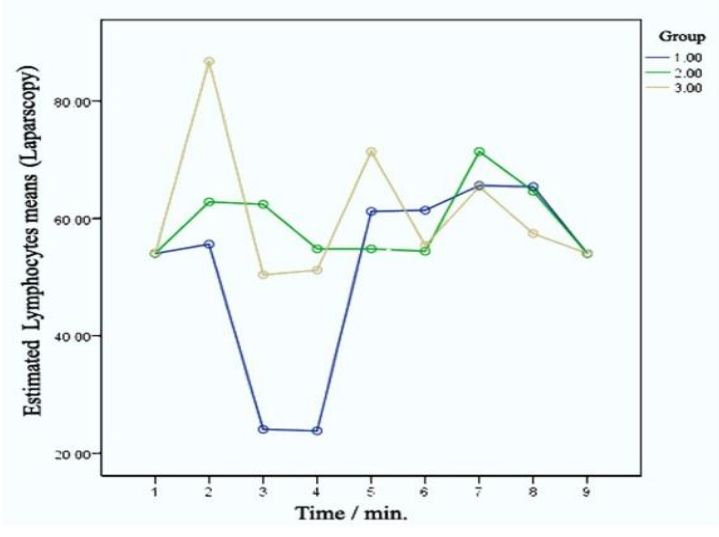

Diagram 8: Lymphocytes between the three groups in laparoscopy

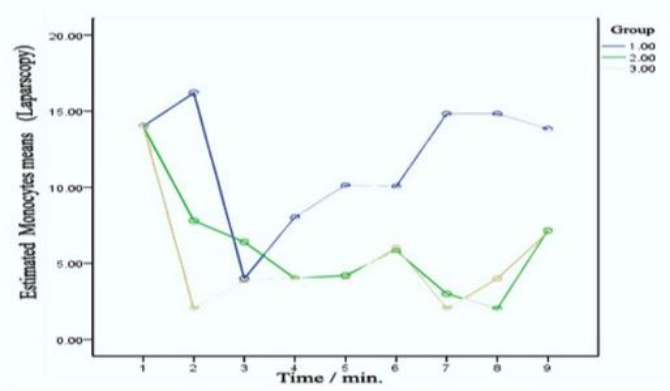

Diagram 9: Monocytes between the three groups in laparoscopy.

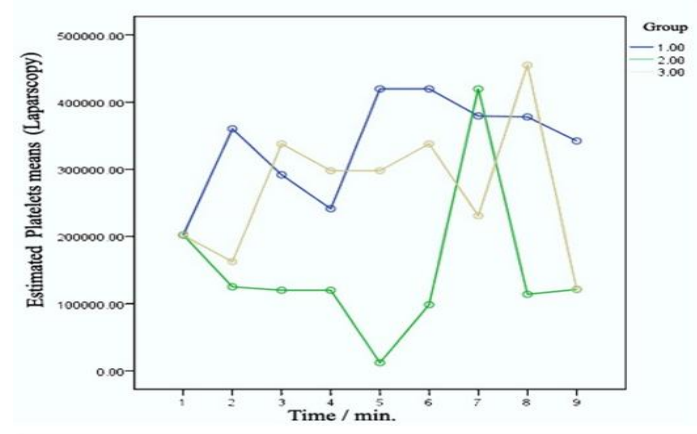

Diagram 10: Plateletcounts between the three groups in laparoscopy 


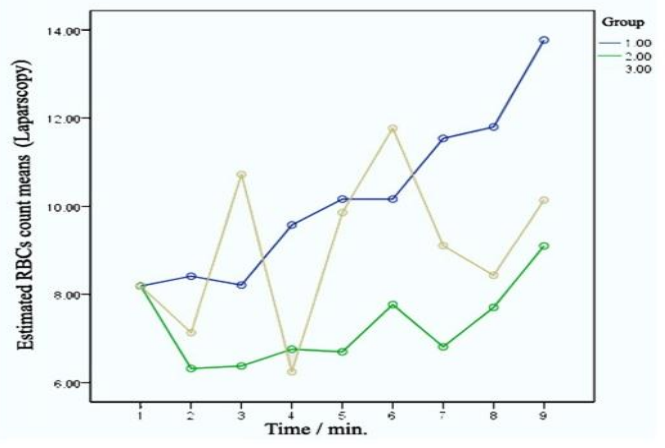

Diagram 11: RBC counts between the three groups in laparoscopy.

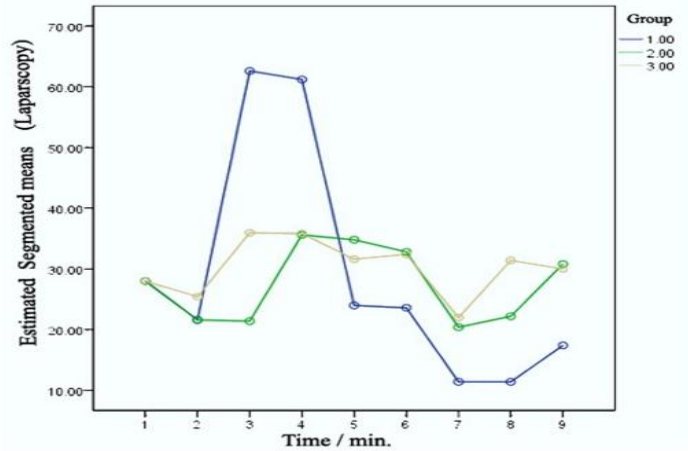

Diagram 12: Segmented cells between the three groups in laparoscopy.

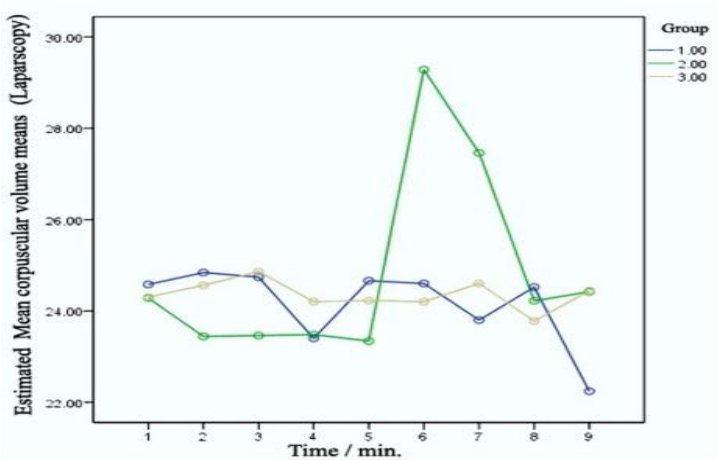

Diagram 13: SPO2 percentages between the three groups in laparoscopy.

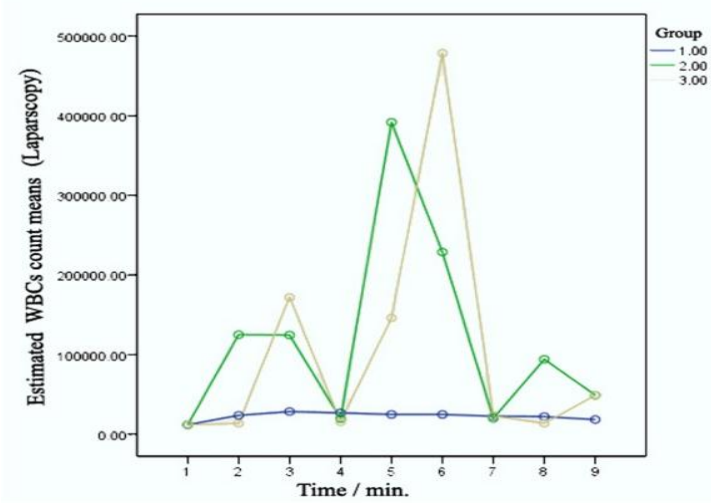

Diagram 14: WBC counts between the three groups in laparoscopy.

\section{Biochemical findings Laparoscopy parameters}

The ALT diagram (15) and AST diagram (15) for all the three groups were not significantly different. Group (III) recorded the highest AST, followed by group (II). Group (II) recorded the highest ALT followed by group (III).

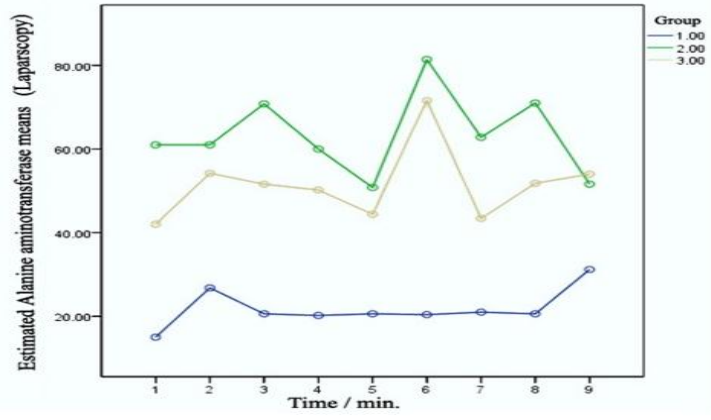

Diagram 15: ALT levels between the three groups in laparoscopy.

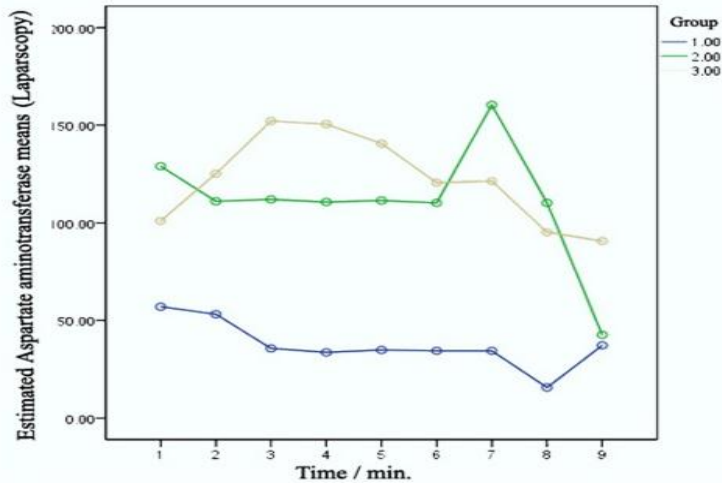

Diagram 16: AST levels between the three groups in laparoscopy.

\section{Hormonal findings \\ Laparoscopy parameters}

The cortisol $(3.6 \pm 0.91)$ levels for groups (I) and (III) were significantly lower than that of group (II). Also, cortisol levels of group (I) did not significantly differ from that of the group III (diagram 17).

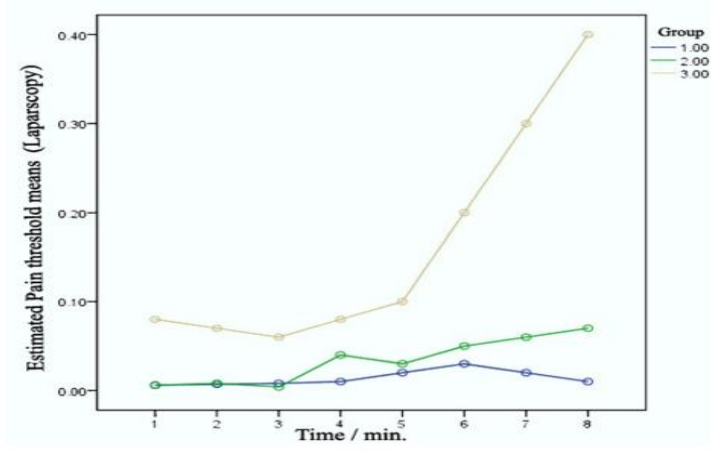

Diagram 17: cortisol levels between the three groups in laparoscopy 


\section{Pain threshold findings \\ Laparoscopy parameters}

The pain threshold levels of the three groups were significantly different from $(0.01 \pm 0.00)$ to $(0.4 \pm$ $0.00)$. Group (III) recorded the highest pain threshold levels $(0.1 \pm 0.00)$, followed by the group II (diagram $18)$.

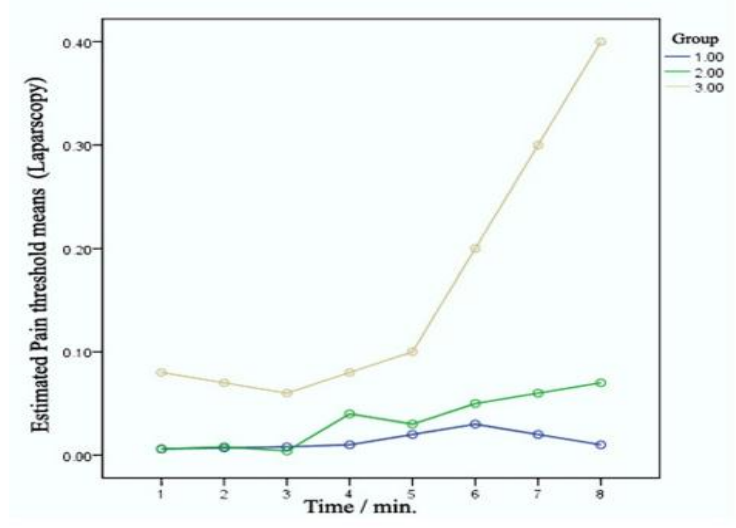

Diagram 18: pain threshold values between the three groups in laparoscopy.

\section{DISCUSSION}

Concerning laparoscopy, there were statistically significant interactions between the groups and the overtime rates of head and neck relaxation $(\mathrm{F}(2,12)=47.87, \mathrm{P}<0.0001)$, and tympany $(\mathrm{F}(2,12)$ $=87.86, \mathrm{P}<0.0001) .=87.86, \mathrm{P}<0.0001)$, tongue protrusion $(\mathrm{F}(2,12)=98.38, \mathrm{P}<0.0001)$, salivation $(\mathrm{F}(2,12)=49.46, \mathrm{P}<0.0001)$, teeth grinding $(\mathrm{F}(2,12)$ $=387.25, \mathrm{P}<0.0001)$, rumen motility $(\mathrm{F}(2,12)=$ $24.52, \mathrm{P}<0.0001)$, and eyelid closure $(\mathrm{F}(4.69,28.15)$ $=26.24, \mathrm{P}<0.0001)$.

Post hoc comparisons between groups using the Bonferroni correction indicated that the ALT, AST, eosinophils, hematocrit, lymphocytes, monocytes, platelets, RBCs, segmented cells, $\mathrm{SpO} 2$, and pain threshold levels for all the three groups were significantly different. Group (III) recorded the highest AST, eosinophils, lymphocytes, segmented cells, and pain threshold levels, followed by group (II). Group (II) recorded the highest $\mathrm{ALT}$ and $\mathrm{SpO} 2$ levels, followed by a group (III). Group (I) recorded the highest hematocrit, monocytes, platelets, and RBCs levels, followed by a group (III).

The physiological variables in laparoscopy have statistically significant interactions between the groups as described by Qu et al. (1996). Group (I) electroacupuncture, showed a significant rise in the rectal temperature, it may be due to initial apprehension of the animal for the needles and the current that believed to have been mediated at the hypothalamic level, and increased basal metabolic rate of animals. To the antifebrile effect is believed to have been mediated at the hypothermic level (Rogers and Bossy, 1981). Nevertheless, electroacupuncture maintains sufficient excitation of the central nervous system (Latimer et al., 2004). However, laparoscopy group (II) and group (III) showed a gradual reduction in temperature that may have been attributable to a decrease in skeletal muscle tone, decrease in metabolic rate, or muscle relaxation along with depression of thermoregulatory centers (Babu et al., 1988).

Heart rate in laparoscopy is superior in the group (II) and group (III), this parasympathetic stimulation affects the cardiovascular system (Lee, et al., 1974) which led to a transient fall in the blood pressure and consequent rise of the heart rate. But in the laparoscopy group (I) maintains heart rate normal till the end of surgery as mentioned by (Sali, 2010).

The respiratory rate of laparoscopy is superior in the group (I), this rise might be attributed to initial apprehension of the animal to the needles and current, and also due to increased heart rate (Wright and McGrath, 1981). However, the group (II) group (III) shows a decrease in respiratory rate, whereas almost all a2-adrenoceptor agonists cause some degree of respiratory depression.

Group (I), group (II), and group (III) in laparoscopic surgery there is no sign of CRT. The bucks of the study have shown a significant increase hematocrit in laparoscopic surgery in the group (II) group (III) then the group (I), showed a steady gradual increase red blood cells increase in laparoscopic surgery there is the group (I) indices confirmed the data published in the National Institutes of Health Conference which stated that acupuncture increases red blood cell, group (II) then the group (III), platelets in laparoscopy significant different decrease in the group (I) and increase group (II) (III) Secondary or reactive thrombocytosis assisted in blood clotting (Habibu et al., 2017), and staff cells in laparoscopic surgery were no significant. The WBC count in laparoscopy is nonsignificant.

Electroacupuncture also can suppress the production of adrenocortical hormones in response to stress Electroacupuncture-induced transient changes in the present study may have been associated with constriction of the splenic sinuses are similar to that reported in normal goats (Egbe-Nwiyi et al., 2000).

The significant increases of blood indices confirmed the data published in the National Institutes of Health Conference which stated that acupuncture 
increases red blood cells and treats thrombocytopenia, and increases immunity, also corresponding with World Health Organization recommendations that endorse acupuncture for treating leukopenia (Pais et al., 2014). The study found increased levels of hematocrits, granulocytes, and monocytes before and after treatment, but this difference is not significant and also, the increases of hematological variables are within the normal values by the study of (Aiello et al., 2016).

Eosinophils in laparoscopic surgery were significantly high in a group (III), then group (II) but the group (I) not significant and maintain it until the end surgery, this helps the movement to inflamed areas, trapping substances, killing cells, anti-parasitic and bactericidal activity, participating in immediate allergic reactions, and altering inflammatory responses (Murphy and Weaver, 2016).

In laparoscopy of groups were significantly different in the group (I) causes an increase in lymphocytes which plays an important role in the immune system, then group (II), and group (III) increased and decreased lymphocyte count (Hwang and Edwards, 1977). The hemoglobin concentration for laparoscopic surgery the group (I), (II) did not significantly differ from that of the group (III). Based on the results of hematologic evaluations, there were no changes in hemoglobin concentration for treated goats (Zahir et al., 2016).

SpO2 levels in laparoscopy for groups (I) and (III) were significantly higher than group (II). The increased permeability induced by oxygen in the alveolar-capillary wall as a development that increased permeability of the endothelial cell lining is needed before circulating antibodies, the oxyhemoglobin dissociation curve describes the relationship between the partial pressure of oxygen and the percent of hemoglobin saturated with oxygen and varies with chemical and physical (Burk and Orr, 2020).

ALT and AST are one of the liver enzymes. It plays a crucial role in metabolism, the process that turns food into energy (Watkins et al., 2006). When elevated ALT levels are found in the blood, the possible underlying causes can be further narrowed down by measuring other enzymes. The ALT and AST levels in laparoscopy for three groups were not significantly different. Serum ALT and AST activities of the goats did not change significantly in laparoscopy (Zahir et al., 2016).

The significant increases in serum cortisol levels after the end of the therapy are attributed to its effect on the central and peripheral nervous systems to activate the body's endogenous or natural pain relief mechanisms. It stimulates the release of several neurotransmitters, chemical secretions that cause a favorable reaction in another nerve, a muscle, or a gland. It also causes a release of $\beta$-endorphins and adrenocorticotropic hormone from the pituitary gland that induces the release of cortisol from the adrenal gland; this is in agreement with (Cadoy and Acorda, 2018).

In the study cortisol level in in Laparoscopy the cortisol levels for groups (I) and (III) were significantly lower than that of the group (II). Also, cortisol levels of the group (I) did not significantly differ from that of the group (III), the cortisol levels are attributed to its effect on the central and peripheral nervous systems to activate the body endogenous or natural pain relief mechanisms. It stimulates the release of several neurotransmitters, chemical secretions that cause a favorable reaction in another nerve, a muscle, or a gland. It also causes a release of $\beta$-endorphins and adrenocorticotropic hormone from the pituitary gland that induces the release of cortisol from the adrenal gland (Habibu et al., 2017). Moreover, Cortisol regulates a wide range of vital processes throughout the body, including metabolism and the immune response. It also has a very important role in helping the body respond to stress (Ramamoorthy and Cidlowski, 2016).

Several investigators measured the pain threshold in bucks with an algesimetry method based on a leg-lifting response to a subcutaneous electric stimulus. This method is not an involuntary reflex but instead represents a learned cognitive behavior. Additionally, this technique could not be used for restrained animals. Potassium iontophoresis is a convenient and reliable pain stimulus that can be provided rapidly and repeatedly with minimal loss inconsistency of a subject's reported pain level (Humphries et al., 1994), this quantitative method to measure pain thresholds. Antinociception induced by electroacupuncture is not sufficiently strong to completely block sharp, acute pain attributable to major surgery in some individuals (Han, 2015). The present work of pain threshold in laparoscopy as a significant different group (III) is higher than the group (II) and the group (I).in bucks. Evidence of electroacupuncture analgesia using 10 newly chosen acupoints can produce sufficient analgesia for right flank laparotomy in bucks.

Group (I) showed improvement in the rates of eyelid closure, head and neck relaxation, rumen motility, and tympany. The respiratory rates, the body temperatures, and capillary fill times for the three groups were not significantly different. Hematocrit, 
Hemoglobin, RBCs, Platelets, and $\mathrm{SpO} 2$ were significant. ALT and AST showed no significance. The cortisol and pain threshold showed a significant difference.

In the present study, the dose of detomidine $(0.03 \mathrm{mg} / \mathrm{kg})$ was calculated on the basis of which it was found to cause deep sedation and antinociception. Electroacupuncture plus detomidine $(0.03 \mathrm{mg} / \mathrm{kg})$ provided an excellent anti-nociceptive effect, and the adverse effects were less. Therefore, the electroacupuncture plus detomidine group, there was reduction of the amount of analgesic required if compared with the amount for the group receiving detomidine without electroacupuncture. The antinociceptive effect induced by electroacupuncture at $20-30 \mathrm{~Hz}$ for 60 minutes is approximately equivalent to the effect for $4 \mathrm{mg}$ of morphine/kg in rats (Tang $\boldsymbol{e t}$ al., 1997). Insufflations by $\mathrm{CO}_{2}$ into the peritoneal cavity to create pneumoperitoneum is a routine technique for abdominal exposure, which improves visualization and facilitates instrumental and visceral manipulation during laparoscopic surgery (Freeman, 1999).

Laparoscopy is widely used in small ruminants as a tool for reproductive studies and application of reproductive technologies such as intrauterine insemination, embryo transfer, oocyte collection, and ovulation rate determination. Laparoscopic procedures to visualize and manipulate the female reproductive tract in small ruminants are easy to learn and present the advantage of being less invasive than complete exteriorization of the genital tract (Leil, 2006). Found that in dorsal recumbent positioned buck and by orienting the laparoscope caudally and in a sagittal plane, the urinary bladder, coiled uterine horns were identified easily without any manipulation. He added that ovaries, then proper ligaments and mesovarium, fallopian tubes and broad ligaments were not observed without manipulation of the overlying segments of gastrointestinal and elevation of the uterus by accessory instruments (ElKhammary, 2008).

\section{CONCLUSIONS}

Based on the current results, it could be concluded that electro acupuncture analgesia using the ten new acupoints and Two-parallel needles, away from each other inserted subcutaneously and muscle layers at the surgery area, can produce sufficient analgesia in the laparoscopy in goats. The electroacupuncture works more potent and achieves sufficient abdominal anaesthesia suitable for goat laparoscopic surgery superior to the other two regimes.

\section{Declaration of Competing interest}

On behalf of all authors, I hereby declare that no conflict of interest may interfere with the publication of the manuscript.

\section{REFERENCES}

AIEllo, S. E., MOSES, M. A. and AlleN, D. G. (2016): The Merck veterinary manual Merck, 31743185.

BABU, D., PRASANNA, V. and LAKSHMIPATHI, G. V. (1988): Studies on acupuncture anaesthesia in sheep with particular reference to abdominal cavity M.V.Sc thesis submitted to Andhra Pradesh Agricultural University, Hy derabad.-517 502.

BURK, K. M., and ORR, J. A. (2020): A procedure for determining subject-specific pulse oxygen saturation response. Medical and Biological Engineering and Computing, 1-9.

CADOY, J. M. and ACORDA, J. A. (2018): Physiological responses, cortisol level and analgesia in goats subjected to exploratory laparotomy under acupuncture and regional analgesia. Philippine Journal of Veterinary Medicine, 55 (1), pp. 35-44.

CELARIER, S., MONZIOLS, S., FRANCOIS, M. O., ASSENAT, V., CARLES, P., CAPDEPONT, M. and DENOST, Q. (2020): Randomized trial comparing low-pressure versus standard-pressure pneumoperitoneum in laparoscopic colectomy: PAROS trial. Trials, 21(1), 1-7.

CHAMNESS, C. J. (2002): Nondisposable instrumentation for equine laparoscopy. In: Fischer, A. T. Editor.Equine diagnostic and surgical laparoscopy (pp. 37-49). WB Saunders, Philadelphia.

DONG, Q. L. and WANG, G. N. (2006): Effect of general anaesthesia with combination of acupuncture and enflurane applied in radical operation of laryngocarcinoma. Chinese journal of integrative medicine, 12(4), 306-309.

EGBE-NWIYI, T. N., NWAOSU, S. C., and SALAMI, H. A. (2000): Haematological values of apparently healthy sheep and goats as influenced by age and sex in arid zone of Nigeria. African Journal of Biomedical Research, 3(2), 109-115.

El-KHAMARY, A. (2008): Studies on the use of surgical laparoscopy in goats. M.V.Sc. Thesis. Fac. Vet. Med. Alexandria Univ.

FREEMAN J. (1999): Operating room, set up, equipment and instrumentation. In Freeman J., editor. Vet. Endosurgery.St. Louis, Missouri: Mosby, 2-23.

GROPPETTI, D., PECILE, A. M., SACERDOTE, P., BRONZO, V. and Ravasio, G. (2011): Effectiveness of electroacupuncture analgesia compared with opioid administration in a dog model: a pilot study. British J. Anaesthesia, 107(4), 612-618.

Habibu, B., Abdullahi, A., Yaqub, L. S., Makun, H. J. and KAWU, M.U. (2017): Variations in Platelet Count and Total Protein in Relation to Differences in Sex, Age, Breed and Reproductive Status of Goats during the Cold-Dry Season (Harmattan). J Dairy Vet Anim Res, 5(3), 00141. 
HAN, J. S. (2015): Acupuncture. In Treatment of Chronic Pain by Integrative Approaches (pp. 123-136). Springer, New York, NY.

HULET, C. V. and FOOTE, W. C. (1968): A rapid technique for observing the reproductive tract of living ewes. Journal of animal science, 27(1), 142145.

HUMPHRIES, S. A., LONG, N. R., and JOHNSON, M. H. (1994): Iontophoretically applied potassium ions as an experimental pain stimulus for investigating pain mechanisms. Perception \& Psychophysics, 56(6), 637-648.

HWANG, Y. C., and EDWARDS, D. J. (1977): Changes in canine leukocyte differential counts following treatments by electro-acupuncture. In anatomical record. Diva john Wiley \& sons Inc. third ave, New York, 189, (3), 544-545.

JANSSENS, L. A., ROGERS, P. A. and SCHOEN, A. M. (1988): Acupuncture analgesia: a review. The Veterinary Record, 122(15), 355-358.

LATIMER, J., MAHER, C., and REFSHAUGE, K. (2004): The attitudes and beliefs of physiotherapy students to chronic back pain. The Clinical journal of pain, 20(1), 45-50.

LEE, D. C., LEE, M. O. and CLIFFORD, D. H. (1974): Cardiovascular effects of acupuncture in anesthetized dogs. The American journal of Chinese medicine, 2(03), 271-282.

LEIL, A. (2006): Laparoscopic investigations of the urogenital system in sheep and goats. Ph.D. Thesis. Fac. Vet. Med. Cairo univ.

LIU, D. M., ZHOU, Z. Y., DING, Y., CHEN, J. G., HU, C. M., CHEN, X. and DING, M. X. (2009): Physiologic effects of electroacupuncture combined with intramuscular administration of xylazine to provide analgesia in goats. American journal of veterinary research, 70(11), 1326-1332.

MURPHY, K. and WEAVER, C. (2016): Janeway's immunobiology. Garland science.

PAIS, I., CORREIA, N., PIMENTEL, I., TELES, M. J., NEVES, E., VASCONCELOS, J. and EFFERTH, T. (2014): Effects of acupuncture on leucopenia, neutropenia, NK, and B cells in cancer patients: a randomized pilot study.Evidence-Based Complementary and Alternative Medicine, p. 9.

PARMEN, V. (2014): Electroacupuncture analgesia in a rabbit ovariohysterectomy. Journal of Acupuncture and Meridian Studies, 7(1), 15-24.

PUGH, D. G., BAIRD, N. N., EDMONDSON, M. and PASSLER, T. (2020): Sheep, Goat, and Cervid Medicine-E-Book. Elsevier Health Sciences.

QU, G. L., ZHUANG, X. L., XU, G. H., YANG, L. F., WANG, Z. T., CHEN, S. L., and XIE, T. (1996): Clinical observation on combined anesthetics acupuncture anesthesia in 50 patients undergoing renal transplantation. Chin J Pain Med, 2, 72-77.

RAMAMOORTHY, S., and CIDLOWSKI, J. A. (2016): Corticosteroids: mechanisms of action in health and disease. Rheumatic Disease Clinics, 42(1), 15-31.

ROGERS, P. A. M. (1995): Acupuncture analgesia for surgery in animals. In: Bryden DI (ed.). Acupuncture in Animals. University of Sydney, pp. 341-352.
ROGERS, P. A. M. and BOSSY, J. (1981): Activation of the defense system of the body in animals and man by acupuncture and moxibustion. Acupunt Res Q, 5, 4754.

SALI, K. M. (2010): Determination of anatomical location to the parts of female genital system of Awassi ewes by using laparoscopy. Journal of Veterinary Anatomy, 3(2), 47-54.

SHETA, E., RAGAB, S., FARGHALI, H. and ELSHERIF, A. (2015): Successful practice of electroacupuncture analgesia in equine surgery. Journal of acupuncture and meridian studies, 8(1), 3039.

SOO-JIN, L., CHANG-SIK, P., MOO-HYUNG, J., NAM-JOONG, K., JAE-IL, L., YOUNG-SUK, K., MYUNG-JIN, K., JAE-YON, L., SEONG-MOK, J., DUCK-HWAN, K. and MYUNG-CHEOL, K. (2005): Acupuncture analgesia for operation in Korean native goats. Korean J Vet Res 45(4) : 581585.

VIRTANEN, R. and MACDONALD, E. (1985): Comparison of the effects of detomidine and xylazine on some a -adrenoceptor-mediated responses in the central and peripheral nervous systems. European J. Pharmacol., 115, 277-284

WANG, B. G., WANG, E. Z., CHEN, X. Z., SUN, F. L. and YANG, E. H. (1995): Transcutaneous electrical acupoint-stimulation potentiates the anesthetic effect of enflurane in humans. Journal of anesthesia, 9(1), 40-43.

WANG, D. W. and JIN, Y. H. (1989): Present status of cesarean section under acupuncture anesthesia in China. Fukushima journal of medical science, 35(2), 45-52.

WATKINS, P. B., KAPLOWITZ, N., SLATTERY, J. T., COLONESE, C. R., COLUCCI, S. V., STEWART, P. W., and HARRIS, S. C. (2006): Aminotransferase elevations in healthy adults receiving 4 grams of acetaminophen daily: a randomized controlled trial. Jama, 296(1), 87-93.

WRIGHT, M. and MCGRATH, C. J. (1981): Physiologic and analgesic effects of acupuncture in the dog. Journal of the American Veterinary Medical Association, 178(5), 502-507.

ZAHIR, S., MAN, L. H., ZHENG, Y. Q., FEI, Y. Z., JIE, Z., JUAN, W., SHAO, W. W., WEI, Z. and MING, X. D. (2016): Physiologic and biochemical effects of electroacupuncture combined with intramuscular administration of dexmedetomidine to provide analgesia in goats. American Journal of Veterinary Research, 77(3), 252-259.

How to cite this article:

Khalifa Ashour, Naglaa Abd Elkader Awad, Sherein Saeid Abdelgayed, Amal $Z$. Leil and Eldessouky Sheta. 2020. Comparison Between Electroacupuncture, Detomidine Plus Electroacupuncture And Detomidine Alone For Laparoscopic Surgery In Goats. Journal of Applied Veterinary Sciences, 5(4): 73 - 83.

DOI: 10.21608/JA VS.2020.120351 